\title{
Higher maternal age at birth was associated with increased self sufficiency of children at age 27 to 33 years
}

Hardy JB, Shapiro S, Astone NM, et al. Adolescent childbearing revisited: the age of inner-city mothers at delivery is a determinant of their children's self-sufficiency at age 27 to 33. Pediatrics 1997 Nov;100:802-9.

\section{Question}

Is the age of inner city mothers a determinant of their children's self sufficiency at age $27-33$ years?

\section{Design}

Cohort study with follow up of $>30$ years (Pathways to Adulthood Study and the Johns Hopkins Collaborative Perinatal Study).

\section{Setting}

Inner city of Baltimore, Maryland, USA.

\section{Participants}

1758 adults ( $82 \%$ black, $54 \%$ women) who were born from 1960-5 and were assessed at birth, 7 or 8 years later, and in 1994. 1552 mothers of the participants were also included.

\section{Assessment of risk factors}

Maternal age at first birth $(<20 \mathrm{y}, 20-24 \mathrm{y}$, and $\geqslant 25 \mathrm{y})$, parity, race, sex of the child, maternal education, poverty status at birth including financial independence of public support, marital and employment status, week of pregnancy when prenatal care was started, gestational age at birth, and birth weight.

\section{Main outcome measures}

Outcomes for children included educational attainment of at least a high school diploma; financial independence (absence of family support from public sources such as Aid to Families with Dependent Children, food stamps in the previous year, and no current eligibility for Medicaid); and delay of first birth until age 20 or later.

\section{Main results}

Younger mothers tended to have less education $(\mathrm{p}<0.001)$; higher rates of poverty $(\mathrm{p}<0.001)$; be more likely to receive welfare ( $\mathrm{p}<0.001)$, be single ( $\mathrm{p}<0.001)$, and be unemployed or never employed ( $\mathrm{p}<0.001$ for both); and were less likely to have had previous live births $(\mathrm{p}<0.001)$. Younger mothers also delivered at a lower gestational age $(\mathrm{p}=0.007)$ and their infants had a lower birth weight $(p=0.002)$. Younger and older mothers did not differ for the week at which they started prenatal care.

Increased maternal age at birth was associated with the child's independence at age 27-33 years measured by attainment of a high school diploma, financial independence of public support, and delay of first birth until after age 20 (table).

The effect of age persisted after adjustment for mother's parity, educational level and poverty status, and the child's sex and race. When race and sex of the children were analysed separately, the results were mixed with respect to self sufficiency.

\section{Conclusion}

At age 27-33 years, children of older mothers ( $\geqslant 25$ y at birth of child) were more likely than those of younger mothers to have completed high school, be financially independent, and to have delayed their first birth beyond teenage years.

Proportion of children with self sufficient behaviour outcomes at age 2733 years by maternal age at birth

\begin{tabular}{lllll}
\hline Outcomes & $<20$ years & $20-24$ years & $\geqslant 25$ years & p value \\
\hline High school diploma & $62 \%$ & $68 \%$ & $72 \%$ & $<0.01$ \\
Financial independence & $72 \%$ & $77 \%$ & $78 \%$ & $<0.05$ \\
Delay of first birth & $68 \%$ & $74 \%$ & $79 \%$ & $<0.001$ \\
\hline
\end{tabular}

Sources of funding: W T Grant Foundation; Robert Wood Johnson Foundation; Johns Hopkins Population Center.

For article reprint:Dr J B Hardy, 550 North Broadway, Suite 508, Baltimore, MD 21205, USA. Fax +14106141885.

\section{Commentary}

Previous research on the long term effects of teenage pregnancy comes primarily from the United States National Longitudinal Survey of Youth. ${ }^{1}$ Findings from that survey indicated that the daughters of adolescent mothers were more likely to become teen mothers than the children of older mothers. This intergenerational risk of teenage pregnancy increased when the mothers were dependent on welfare assistance.

Hardy et al found that children of older mothers ( $\geqslant 25 \mathrm{y}$ of age at child birth) had the greatest probability of adult self sufficiency and children of teenage mothers had the least. What are possible reasons for this? Older maternal age may be associated with increased social maturity, which may contribute to improved parenting quality. Older mothers may also be more likely to be married and employed, and to have more adequate financial resources.

Readers must exercise caution when interpreting these data. The research has limitations including the nonrepresentativeness of the study population (most were poor or near poor), large follow up losses (23\%), and recall bias. Strengths of the study include the prospective collection of data from pregnancy and birth to age 8 , the inclusion of many direct observations, and the concurrent collection of outcomes. Data about late childhood and adolescence were collected retrospectively. The data may have limited applicability because of the different patterns of teenage pregnancy in various countries. The study does, however, contribute to our understanding of the long term consequences of adolescent childbearing.
The findings of this study are relevant to nurses working in community, primary care, and acute care settings. This research is also of interest to economists, midwives, policy makers, physicians, and social workers. The results emphasise that conditions in one generation may affect children in the next. Because multiple factors influence children's long term outcome, there is a need to consider combinations of potential risk factors when planning interventions to improve the life chances of mothers and children.

Debbie Sheehan, RN, MSW

Program Manager, Hamilton-Wentworth Regional Public Health Department Hamilton, Ontario, Canada

1 Furstenberg FF, Levine JA, Brooks-Gunn J. The children of teenage mothers: patterns of early childbearing in two generations. Fam Plann Perspect 1990;22:54-61. 